\title{
BMJ
}

\section{Community based integrated intervention for prevention and management of chronic obstructive pulmonary disease (COPD) in Guangdong, China: cluster randomised controlled trial}

\author{
Yumin Zhou, medical doctor, ${ }^{1}$ Guoping Hu, medical doctor, ${ }^{1}$ Dali Wang, physician, ${ }^{2}$ Shaoyi Wang, professor, ${ }^{3}$ \\ Yujun Wang, professor, ${ }^{3}$ Zhigang Liu, professor, ${ }^{3}$ linxin Hu, medical doctor, ${ }^{1}$ Zhe Shi, medical doctor, ${ }^{1}$ \\ Gongyong Peng, medical doctor, ${ }^{1}$ Shengming Liu, professor, ${ }^{1,4}$ Jiachun Lu, professor, ${ }^{5}$ Jingping Zheng, \\ professor, Jian Wang, professor, ${ }^{1,6}$ Nanshan Zhong, professor, ${ }^{1}$ Pixin Ran, professor ${ }^{1}$
}

\begin{abstract}
${ }^{1}$ State Key Laboratory of
Respiratory Disease, Guangzhou Institute of Respiratory Diseases,

First Affiliated Hospital, Guangzhou Medical University, Guangzhou,

Guangdong, China

${ }^{2}$ Second Hospital of Liwan District

of Guangzhou, Guangzhou,

Guangdong

${ }^{3}$ Bureau of Environmental Protection of Liwan District,

Guangzhou Environmental

Monitoring Center, Bureau of

Environmental Protection of

Guangzhou Municipality,

Guangdong

${ }^{4}$ First Affiliated Hospital of Jinan University, Guangzhou,

Guangdong

${ }^{5}$ Department of Epidemiology, Guangzhou Medical University, Guangzhou, Guangdong

${ }^{6}$ Division of Pulmonary and Critical Care Medicine, Johns Hopkins University School of Medicine, Baltimore, MD, USA Correspondence to: $\mathrm{P}$ Ran pxran@gzhmc.edu.cn and N Zhong
\end{abstract} nanshan@vip.163.com

Cite this as: BMJ 2010;341:c6387 doi:10.1136/bmj.c6387

\section{ABSTRACT}

Objective To evaluate the effects of a community based integrated intervention for early prevention and management of chronic obstructive pulmonary disease (COPD) in China.

Design Cluster randomised controlled trial. Setting Eight healthcare units in two communities. Participants Of 1062 people aged 40-89, 872 (101 with COPD and 771 without COPD) who fulfilled the inclusion and exclusion criteria were allocated to the intervention or the usual care programmes.

Intervention Participants randomly assigned to integrated intervention (systematic health education, intensive and individualised intervention, treatment, and rehabilitation) or usual care.

Main outcome measures Annual rate of decline in forced expiratory rate in one second $\left(\mathrm{FEV}_{1}\right)$ before use of bronchodilator.

Results Annual rate of decline in $\mathrm{FEV}_{1}$ was significantly lower in the intervention community than the control community, with an adjusted difference of $19 \mathrm{ml} /$ year (95\% confidence interval 3 to 36$)$ and $0.9 \%(0.1 \%$ to $1.8 \%$ ) of predicted values (all $\mathrm{P}<0.05$ ), as well as a lower annual rate of decline in $\mathrm{FEV}_{1} / \mathrm{FVC}$ (forced vital capacity) ratio (adjusted difference $0.6 \%(0.1 \%$ to $1.2 \%) \mathrm{P}=0.029)$. There were also higher rates of smoking cessation $(21 \% \mathrm{~V}$ $8 \%, P<0.004)$ and lower cumulative death rates from all causes ( $1 \%$ v $3 \%, \mathrm{P}<0.009)$ in the intervention community than in the control community during the four year followup. Improvements in knowledge of COPD and smoking hazards, outdoor air quality, environmental tobacco smoke, and working conditions were also achieved (all $\mathrm{P}<0.05)$. The difference in cumulative incidence rate of COPD (both around 4\%) and cumulative death rate from COPD ( $2 \% v 11 \%)$ did not reach significance between the two communities.

Conclusions A community based integrated intervention can have a significant impact on the prevention and management of COPD, mainly reflected in the annual rate of decline in $\mathrm{FEV}_{1}$.

Trial registration Chinese Clinical Trials Registration (ChiCTR-TRC-00000532).

\section{INTRODUCTION}

Chronic obstructive pulmonary disease (COPD) has become a major public health problem worldwide because of its high and increasing prevalence, morbidity, and mortality. ${ }^{12}$ A recent report estimated that the global prevalence of COPD (stage II or over) is about $10 \%\left(12 \%\right.$ in men and $9 \%$ in women). ${ }^{3}$ In China, COPD affects $8 \%$ of the population aged 40 or above $^{4}$ and is one of the top diseases in the World Health Organization's ranking of burden of diseases. ${ }^{5}$ It is therefore necessary to develop a reliable intervention strategy for prevention and management of COPD to reduce the burden of this disease.

Current interventions for COPD (such as smoking cessation, rehabilitation, nutrition support, drug treatments, and psychosocial aids) are mainly carried out in hospitals on a case by case basis among patients who have already developed moderately or severely symptomatic COPD, while little attention has been paid to community based integrated interventions for earlier stages of the disease or before it has developed. Though there has been some progress with case based or hospital based interventions (such as improvements in exercise capacity, forced expiratory volume in one second $\left(\mathrm{FEV}_{1}\right)$, and health related quality of life, fewer admissions to hospital and acute exacerbations, and lower all cause mortality), ${ }^{6-10}$ the efficacy of such efforts are limited in the prevention of COPD among the general population in China. Few patients are diagnosed until they develop severe symptoms and signs, and pulmonary function tests are not routinely performed. ${ }^{4}$ 
We carried out a four year community based integrated intervention study to establish a reliable strategy for prevention and management of COPD at its early stages or before its development.

\section{METHODS \\ Sampling and randomisation strategy}

This community based cluster randomised controlled trial ran from September 2002 to May 2007 in Guangzhou city, China. A multistage randomised sampling strategy was used. Based on our previous epidemiological study, ${ }^{4}$ we used computer generated random selection to select one district (Liwang) from 12 districts in Guangzhou city and two communities (Xichun and Nanyuan) from nine comparable communities in the selected district (Liwang). Each was assigned to intervention or control by simple randomisation (a coin toss). We then used a computer generated random list to randomly select five of 15 healthcare units in Xichun and five of 17 healthcare units in Nanyuan for baseline survey. Two of the 10 healthcare units were excluded because they did not complete the baseline survey or refused the follow-up steps. A healthcare unit is a typical office unit in the community. From all the people in the units aged 40 and over, we selected about half $(\mathrm{n}=1062)$ using a systematic sampling method according to the house number. All sampled subjects were invited to participate in the study by a phone call or home visits. We allocated 872 people who fulfilled the inclusion criteria to integrated intervention or usual care in local communities. They underwent follow-up interviews with questionnaires and spirometry tests in the same hospital at baseline and follow-up survey. We also evaluated improvements in awareness of health knowledge related to COPD in random samples drawn from the two communities by using the same systematic sampling method (house number).

Table 1|Baseline characteristics within healthcare units. Figures are numbers (percentages) unless stated otherwise

\begin{tabular}{|c|c|c|}
\hline & Intervention community & Control community \\
\hline No of units & 4 & 4 \\
\hline Total targeted population aged $>40$ & 2432 & 2544 \\
\hline Mean (SD) population aged $>40$ per unit & $608(43)$ & $636(42)$ \\
\hline Mean (SD) annual income* per unit & $17425(608)$ & $17031(190)$ \\
\hline Men & $1218(50)$ & $1269(50)$ \\
\hline Age $\geq 60$ & $994(41)$ & $1071(42)$ \\
\hline$\ll 6$ years' education & $970(40)$ & $1043(41)$ \\
\hline Current smokers & $203(22)$ & $209(23)$ \\
\hline Aware of COPD†‡ & $40(20)$ & $37(18)$ \\
\hline \multicolumn{3}{|l|}{ Aware of hazards of smoking†: } \\
\hline Not aware & $37(18)$ & $38(18)$ \\
\hline Know a little & $76(37)$ & $93(39)$ \\
\hline Know more & $90(44)$ & $90(43)$ \\
\hline
\end{tabular}

COPD=chronic obstructive pulmonary disease.

*yuan/person/year; 1 yuan=£0.09, €0.11, \$0.15.

tData from random sample of 424 (203 in intervention community, 221 in control community) who completed

short questionnaire of knowledge on health.

‡Data before intervention were missing for two people.

\section{Participants}

All included participants aged 40-89 in these two communities underwent a baseline screening survey to evaluate their potential to complete all the acceptable spirometry tests. They then completed questionnaires and gave written informed consent. Exclusion criteria included diagnosis with active tuberculosis, asthma or obvious bronchiectasis, cystic fibrosis, interstitial lung disease, or pulmonary thromboembolic disease; malignant tumour; history of thoracotomy with pulmonary resection; and uncontrolled or serious diseases and others that could potentially affect the spirometry test. Participants were lost to follow-up if we could not contact them or they had moved to another place, withdrew consent, refused to proceed, had invalid data, and were unable to complete the study.

\section{Integrated intervention}

Three groups in the intervention community ("healthy" population, high risk group, and patients with COPD classified by a baseline investigation) received the integrated intervention, including systematic health education and intensive and individualised intervention, treatment, and rehabilitation. To improve outdoor air quality in the intervention community, residents and the research team made intensive appeals to the local administration for relocation and technological upgrading of a neighbourhood cement factory. Because of these joint efforts, the cement factory received technological upgrading targeted to reduce air pollution and, in 2005, during the second year and third year of the intervention, relocated to suburban area more than $70 \mathrm{~km}$ away.

All participants underwent regular systematic health education - with health manuals, bulletins, broadcast television, video, networks, lectures, free consultation, and holding of relevant knowledge competitionsaimed at improving knowledge about COPD, eliminating unhealthy habits and behaviours, and improving indoor and outdoor air quality.

To maximise the effects of the intervention, individuals with COPD and those at high risk received additional and intensive interventions quarterly in the first year and annually in the next three years. These consisted of advice and instructions for smoking cessation, recommendations for better stoves, kitchen ventilation, work environment and living environment, and encouragement on adequate exercises. For smoking cessation we made smokers aware of the adverse effects of smoking on health and the benefits of not smoking, then assessed each smoker's willing to stop smoking and persuaded them to quit. Finally, we made personalised plans for each smoker who was willing to quit smoking. Regular telephone or home visits were performed every three months in the first year and annually thereafter to check smoking status and exposure to other risk factors, as well as to encourage compliance. To prevent relapses, we held advisory and recreational activities, lectures, and provided psychosocial support to help and teach smokers how to cope with withdrawal symptoms such as stress and increases 
in body weight during smoking cessation. Nicotine replacement therapy (such as smoking cessation tea and patches) was recommended to relieve cravings for tobacco and withdrawal symptoms.

In addition, eligible patients with COPD were regularly prescribed a compound bronchodilator (Combivent; salbutamol $120 \mu \mathrm{g} /$ puff and ipratropium $20 \mu \mathrm{g} /$ puff) for a year and received quarterly visits. Pulmonary rehabilitation (such as physical exercise, pursed lip breathing, and abdominal breathing), ${ }^{9}$ low carbohydrate and high protein diets, and other non-pharmacological treatments were also recommend, and patients were helped to make plans in terms of training methods, duration of exercise, and intensity according to guideline. The box summarises the content of the integrated intervention.

\section{Usual care}

Participants in control communities were treated by healthcare providers or general practitioners in the usual manner. In case of deterioration, participants were treated with drugs by following the guidelines from the global initiative for chronic obstructive lung disease (GOLD) or referral to a respiratory specialist. The content and number of usual care services were not standardised.

\section{Components and timings of integrated intervention}

All participants (healthy population, those at high risk of COPD, patients with COPD)

\section{Systematic health education}

Items or components:

- Smoking hazards and instruction for smoking cessation

- Knowledge of COPD and relative risk factors

Scheme or timings:

- Health manuals, bulletins, etc, in public places quarterly

- A lecture and a large scale free consultation twice a year

- A competition of knowledge and free spirometry annually

Participants at high risk of COPD, patients with COPD

\section{Intensive and individualised interventions}

Items or components:

- Advice and instruction for smoking cessation

- Advice to improve air pollution and work environment

- Encouragement to exercise and improvement in living environment

Scheme or timing:

- A lecture, a club activity, and a visit quarterly in the first year and annually thereafter

Patients with COPD only

\section{Treatment and rehabilitation}

Items or components:

- Treatment with compound bronchodilator for a year

- Advice and guidance for individualised rehabilitation, drug use, and diet

- Questionnaire and spirometry quarterly in the first year and annually thereafter

\section{Scheme or timing}

- A visit each quarter in the first year for treatment with compound bronchodilator, advice, and guidance
Baseline and follow-up survey and outcomes measurement All participants filled in questionnaires and underwent spirometry at the baseline and at annual follow-up survey. Considerable efforts were made to ensure high quality data (see appendix 1 on bmj.com). Our primary outcome was the annual rate of decline in $\mathrm{FEV}_{1}$ before use of a bronchodilator in the two communities. The secondary outcomes included changes in cumulative incidence rate, cumulative case death rate for COPD, change in awareness of knowledge related to COPD, and change of risk factors for COPD (such as active and passive smoking, outdoor air pollution, living and working environment) from baseline in the two communities.

\section{Questionnaires}

The questionnaires used at baseline and follow-up visits had previously been used in the Burden of Obstructive Lung Disease study in Guangzhou ${ }^{3}$ and COPD epidemiological survey in $\mathrm{China}^{411}$ (see appendix 2 on bmj.com). Additional questionnaires (COPD management and St George's respiratory questionnaire, SGRQ) were used for patients with COPD. We assessed and classified changes in risk factors (such as active and passive smoking, outdoor air pollution, living and working environment) from baseline as improved, no change, or worse, based on participants' self report. From 2002 to 2007 the local bureau of environmental protection and environmental monitoring centre continuously measured concentrations of sulphur dioxide $\left(\mathrm{SO}_{2}\right)$, nitrogen dioxide $\left(\mathrm{NO}_{2}\right)$, dust deposition, and sulphation rate with an auto-monitoring system.

We classified participants' smoking status at each visit as never smoked, smoking cessation (namely, former smoking), and current smoker. Participants who had smoked for at least six months or had smoked at least 100 cigarettes in their lifetime were defined as an ever smoker, ${ }^{12}{ }^{13}$ otherwise they were classed as never smoking. Current smokers were those who were smoking tobacco products at the time of the survey and included continual and intermittent smokers and those who had quit but restarted or relapsed or had quit but for less than six months. Smoking cessation (former smoking) was defined as having not smoked tobacco products for at least six months at the time of survey. We give the rate of smoking cessation during the study period as the ratio of numbers who gave up smoking during the study period to the numbers of current smokers at baseline. Environmental tobacco smoke was assessed by asking participants whether they could smell tobacco smoke at home or at work for at least an hour a day at each visit. ${ }^{13}$ We classified this by improvement (including no exposure and decreased exposure from baseline) or no improvement (the same and increased exposure from baseline) based on self reports. Exposure to occupational dusts/gases/ fumes for more than a year over a participant's lifetime was deemed as having occupational exposure.

\section{Spirometry}

Trained technicians performed spirometry in accordance with the criteria recommended by the American 


\begin{tabular}{|c|c|}
\hline \multicolumn{2}{|c|}{ Districts randomly selected from 12 districts in Guangzhou city ( $\mathrm{n}=1,9$ communities) } \\
\hline \multicolumn{2}{|c|}{$\downarrow$} \\
\hline \multicolumn{2}{|c|}{ Communities randomly selected ( $n=2,32$ healthcare units) } \\
\hline Baseline survey & \\
\hline \multicolumn{2}{|c|}{ Healthcare units randomly selected for baseline survey ( $n=10,5$ per community) } \\
\hline & $\longrightarrow$ Healthcare units uncompleted/refused $(n=2)$ \\
\hline \multicolumn{2}{|c|}{ Healthcare units enrolled to intervention ( $n=8,4$ per community) } \\
\hline \multicolumn{2}{|c|}{$\downarrow$} \\
\hline \multicolumn{2}{|c|}{ Communities randomised $(n=2)$} \\
\hline Allocation & $\downarrow$ \\
\hline Community allocated to intervention $(n=1)$ & Community allocated to usual care $(n=1)$ \\
\hline $\begin{array}{l}\text { Received allocated intervention } \\
(4 \text { healthcare units, } 436 \text { participants) }\end{array}$ & Received allocated intervention \\
\hline Did not receive allocated intervention & Did not receive allocated usual care \\
\hline ( 0 healthcare units, 87 participants) & (0 healthcare units, 103 participants) \\
\hline $\begin{array}{l}\text { Unreachable/died before intervention } \\
(n=30,6 \%)\end{array}$ & $\begin{array}{l}\text { Unreachable/died before intervention } \\
(\mathrm{n}=33,6 \%)\end{array}$ \\
\hline Refused $(n=27,5 \%)$ & Refused $(n=46,9 \%)$ \\
\hline Invalid data at baseline survey $(\mathrm{n}=30,6 \%)$ & Invalid data at baseline survey $(n=24,5 \%)$ \\
\hline Follow-up & 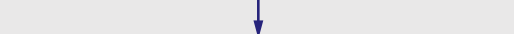 \\
\hline Completed follow-up: & Completed follow-up: \\
\hline 1 year: 417 participants & 1 year: 428 participants \\
\hline 2 year: 409 participants & 2 year: 415 participants \\
\hline 3 year: 401 participants & 3 year: 414 participants \\
\hline 4 year: 409 participants & 4 year: 410 participants \\
\hline $\begin{array}{l}\text { Uncompleted follow-up participants: } \\
1 \text { year: } 16 \text { missing; } 3 \text { withdrew consent; } 0 \text { died } \\
\text { (total 19) }\end{array}$ & $\begin{array}{l}\text { Uncompleted follow-up participants: } \\
1 \text { year: } 6 \text { missing; } 2 \text { withdrew consent; } 0 \text { died } \\
\text { (total 8) }\end{array}$ \\
\hline $\begin{array}{l}2 \text { year: } 22 \text { missing; } 4 \text { withdrew consent; } 1 \text { died } \\
\text { (total 27) }\end{array}$ & $\begin{array}{l}2 \text { year: } 15 \text { missing; } 3 \text { withdrew consent; } 3 \text { died } \\
\text { (total 21) }\end{array}$ \\
\hline $\begin{array}{l}3 \text { year: } 25 \text { missing; } 6 \text { withdrew consent; } 4 \text { died } \\
\text { (total 35) }\end{array}$ & $\begin{array}{l}3 \text { year: } 10 \text { missing; } 3 \text { withdrew consent; } 9 \text { died } \\
\text { (total 22) }\end{array}$ \\
\hline $\begin{array}{l}4 \text { year: } 15 \text { missing; } 6 \text { withdrew consent; } 6 \text { died } \\
\text { (total 27) }\end{array}$ & $\begin{array}{l}\begin{array}{l}4 \text { year: } 8 \text { missing; } 3 \text { withdrew consent; } 15 \text { died } \\
\text { (total 26) }\end{array}\end{array}$ \\
\hline Analysis & $\downarrow$ \\
\hline $\begin{array}{l}\text { Analysis ( } 4 \text { healthcare units): } \\
\text { Questionnaires }(n=436) \\
\text { Spirometry }(n=429)\end{array}$ & $\begin{array}{l}\text { Analysis ( } 4 \text { healthcare units): } \\
\text { Questionnaires }(n=436) \\
\text { Spirometry }(n=431)\end{array}$ \\
\hline $\begin{array}{l}\text { Excluded from spirometry analysis } \\
7 \text { with invalid data }\end{array}$ & $\begin{array}{l}\text { Excluded from spirometry analysis } \\
5 \text { with invalid data }\end{array}$ \\
\hline
\end{tabular}

Fig 1| Flow of participants through trial. Missing indicates participants with missing data because of failure of contact, being out, or inability to finish spirometry test; they might attend next follow-up visits. Withdrew indicates cumulative number of participants who withdrew consent (refusal); they were invited to complete investigation with questionnaire before dropping out

Thoracic Society ${ }^{14}$ and the Europe Respiratory Society. ${ }^{15}$ At least three acceptable and two reproducible measurements (that is, largest and next largest values of forced vital capacity $(\mathrm{FVC})$ and $\mathrm{FEV}_{1}$ within $150 \mathrm{ml}$ or $5 \%$ ) that met with the criteria ${ }^{1415}$ were required for each individual. The largest value of FVC and $\mathrm{FEV}_{1}$ was reported (see appendix 1 on bmj.com). To minimise the variation of the results, on each of the four testing days during the four year study (one day a year) spirometry was performed for each participant at about the same time of day. The use of short and long acting bronchodilators was prohibited within 12 or 24 hours before the test, respectively. A portable spirometer (Micro Medical, Chatham, Kent) was used and the test was done after inhalation of 400 $\mu \mathrm{g}$ of salbutamol for 15-20 minutes (Ventolin,
GlaxoSmithKline) via a $500 \mathrm{ml}$ spacer for those participants whose $\mathrm{FEV}_{1} / \mathrm{FVC}$ ratio before bronchodilation was $<70 \%$. Definition of COPD and its severity stages were according to the global initiative for chronic obstructive lung disease. ${ }^{16}$ We used reference values from the European Coal and Steel Community 1993 for predicted values of $\mathrm{FEV}_{1}$, adjusted with conversion factors for the Chinese population (male 0.95 and female 0.93$).{ }^{17}$

\section{Statistical analysis}

To detect the difference of 20 (SD 80) $\mathrm{ml}^{\text {in }} \mathrm{FEV}_{1}$ between two groups with $80 \%$ power, a two sided type I error of $5 \%$, a design effect of 2.2 , and an intracluster correlation coefficient (ICC or $\rho$, defined as the ratio of the variance between groups to the total variance) of 0.012 based on a pilot study, we calculated that we needed eight clusters of 130 participants according to usual formula, ${ }^{18}$ allowing $20 \%$ loss during follow-up. The statistical analysis was performed with the SAS version 9.1 software (SAS Institute, Cary, $\mathrm{NC})$.

We included in the analyses all recruited participants who had received the allocated intervention or usual care, except those without any acceptable observation data after randomisation. Baseline characteristics were evaluated with a $t$ test or analysis of variance for continuous variables and a $\chi^{2}$ test for dichotomous variables. Improvements in awareness and risk factors for COPD between the two communities were analysed with hierarchical logistic models, taking account of the clustering nature of the data. The latest valid values with respect to change of awareness and risk factors for COPD were regarded as the endpoint values for those who did not complete follow-up.

Preliminary data analysis showed that the pattern of change in absolute values of $\mathrm{FEV}_{1}(\mathrm{ml})$, percentage of predicted value, and $\mathrm{FEV}_{1} / \mathrm{FVC}$ ratio (\%) from baseline was about linear and varied according to baseline data. To access longitudinal changes of $\mathrm{FEV}_{1}$ (often called $\mathrm{FEV}_{1}$ "slope") between the intervention and control community, we applied SAS's Proc Mixed procedure, which admits missed values, to build multilevel mixed models by adjusting for confounding and clustering effects. Potential confounders were taken into account, and we included baseline $\mathrm{FEV}_{1}$ (or $\mathrm{FEV}_{1}$ /FVC ratio), age, sex, education, smoking status, environmental tobacco smoke, COPD, body mass index (BMI), and occupational exposure to dusty/ gases/fumes in the final model. The selection of the appropriate type of covariance structure was accomplished by considering the biological features of the outcome variable and also by choosing the smallest Akaike's information criterion (AIC) after fitting models with alternative covariance structures. The final models included an auto regressive order 1 structure covariance $(\mathrm{AR}(1))$ to count for serial correlation of $\mathrm{FEV}_{1}$ and $\mathrm{FEV}_{1} / \mathrm{FVC}$ within individuals and an unstructured covariance to account for random variation in the intercept and slope parameters between 
Table 2 | Baseline characteristics of participants randomly selected from two communities. Figures are numbers (percentages) unless stated otherwise

\begin{tabular}{|c|c|c|}
\hline & Intervention community & Control community \\
\hline No of participants & 436 & 436 \\
\hline Men & $211(48)$ & $188(43)$ \\
\hline \multicolumn{3}{|l|}{ Age (years): } \\
\hline Mean (SD) & $60.15(11.31)$ & $60.38(11.53)$ \\
\hline$<60$ & $205(47)$ & $192(44)$ \\
\hline$\geq 60$ & $231(53)$ & $244(56)$ \\
\hline \multicolumn{3}{|l|}{ Years of education: } \\
\hline$<6$ & $187(43)$ & $205(47)$ \\
\hline 6-9 & $106(24)$ & $113(26)$ \\
\hline$\geq 10$ & $143(33)$ & $118(27)$ \\
\hline \multicolumn{3}{|l|}{ BMI: } \\
\hline Mean (SD) & $22.89(3.45)$ & $22.77(3.66)$ \\
\hline$<18.5$ & $40(9)$ & $42(10)$ \\
\hline$\geq 18.5$ & 396 (91) & 394 (90) \\
\hline Mean (SD) FEV $1(\mathrm{l})$ & $2.03(0.62)$ & $2.04(0.63)$ \\
\hline Mean (SD) \% predicted FEV 1 & $88.72(19.45)$ & $90.91(20.69)$ \\
\hline Mean (SD) FVC (I) & $2.59(0.72)$ & $2.56(0.72)$ \\
\hline Mean (SD) \% predicted FVC & $94.66(18.59)$ & $96.20(18.74)$ \\
\hline $\mathrm{FEV}_{1} / \mathrm{FVC}$ ratio (\%)* & $78.27(10.03)$ & $79.44(9.88)$ \\
\hline \multicolumn{3}{|l|}{ Distribution of COPD and non-COPD†: } \\
\hline Healthy population & $106(24)$ & $92(21)$ \\
\hline High risk for COPD & $282(65)$ & $291(67)$ \\
\hline Stage I COPD & $9(2)$ & $10(2)$ \\
\hline Stage II COPD & $24(6)$ & $24(6)$ \\
\hline Stage III COPD or over & $15(3)$ & $19(4)$ \\
\hline Reversibility among COPD $\ddagger$ & $5(10)$ & 7 (13) \\
\hline Previous diagnosis of respiratory disorders & $76(17)$ & $83(19)$ \\
\hline Respiratory symptoms & $157(36)$ & $153(35)$ \\
\hline Occupational history of dusts/gases/fumes§ & $150(34)$ & $249(57)$ \\
\hline Respiratory infection during childhood & $15(3)$ & $20(5)$ \\
\hline \multicolumn{3}{|l|}{ Smoking status at baseline survey: } \\
\hline Never smoker & $241(55)$ & $235(54)$ \\
\hline Smoking cessation & 77 (18) & $63(14)$ \\
\hline Current smoker & $118(27)$ & $138(32)$ \\
\hline Smoking amounts (pack years) & $13.04(21.39)$ & $14.31(21.80)$ \\
\hline Exposed to environmental tobacco smokeף & $302(70)$ & 315 (73) \\
\hline
\end{tabular}

$\mathrm{BMI}=$ body mass index; $\mathrm{FEV}_{1}=$ forced expiratory volume in one second; $\mathrm{FVC}=$ forced vital capacity; $\mathrm{COPD}=$ chronic obstructive pulmonary disease.

*Lower in participants without COPD in intervention community than in control community (80.71 (7.95) v 82.47 (6.76), $P=0.001)$.

†Post-bronchodilator data used in participants with COPD; bronchodilation not carried out those without COPD. $\ddagger$ Reversibility of COPD defined as improvement in $\mathrm{FEV}_{1}$ from pre-bronchodilator $\geq 12 \%$ and $\geq 200 \mathrm{ml}$ postbronchodilator.

$\S$ Two communities had similar characteristics at baseline except for occupational history of dust/gases/fumes (P<0.001).

IData missing for 12 participants (seven in intervention community and five in control community).

individuals and healthcare units. Such an analysis was repeated in subgroups.

We used a mixed model to compare the change in air pollutants (log transformed) in the two communities. As preliminary analysis showed significant or close to significant correlations between pairs of pollutants (data not shown), they can be regarded as a correlated "package" of pollutants with a similar pattern relative to each other across the four year study period. We extracted a variable to represent these air pollutants using factor analysis for $\mathrm{SO}_{2}, \mathrm{NO}_{2}$, dust deposition, and sulphation rate. The correlation of adjusted $\mathrm{FEV}_{1}$ at each year with average level of air pollutants from baseline was analysed with partial correlations analysis. Significance was set at $\mathrm{P}<0.05$.

\section{RESULTS}

Baseline characteristics and follow-up rate

Of 1062 sampled participants, 872 (82\%) who fulfilled the criteria of study were allocated intervention or usual care. Of these, $845(80 \%)$ completed follow-up at the first year, $824(78 \%)$ at the second year, 815 $(77 \%)$ at the third year, and $819(77 \%)$ at the fourth year. A total of $872(82 \%)$ completed the baseline survey and at least one follow-up investigation with questionnaires $(83 \%$ in the intervention community and $81 \%$ in the control community), and $860(80 \%)$ had acceptable data for spirometry test from at least two follow-up visits (including baseline) (82\% in the intervention community and $80 \%$ in the control community) (fig 1). There were 840, 822, and 793 participants who completed an acceptable spirometry test for three, four, and five years (including baseline), respectively.

There was no difference in causes of allocation failure between the two communities $(\mathrm{P}=0.11$, fig 1$)$ and no difference in the main basic demographic characteristics (see table A in appendix 3 on bmj.com). There was a significant difference in causes of uncompleted follow-up (dropping out) for spirometry tests between the communities at the end of study $(\mathrm{P}=0.03$, fig 1$)$. The two communities were drawn from a single district and were similar in socioeconomic status (that is, annual averaged income and education level), availability of and access to health services, current smoking prevalence, awareness of COPD, and main demography at baseline (table 1). At baseline the intervention community had a higher concentration of $\mathrm{SO}_{2}$ and sulphation rate in outdoor air than the control community $(\mathrm{P}<0.001$ and $\mathrm{P}=0.018$, respectively), but there was no difference at the end of study (fig 2). Compared with the control community, the intervention community had a greater rate of decline in $\mathrm{SO}_{2}$ concentration $\left(0.051 \mu \mathrm{g} / \mathrm{m}^{3}\right.$ per year $(95 \%$ confidence interval 0.019 to 0.083$) \mathrm{P}=0.003)$ and dust deposition $(0.051$ (0.019 to $0.083) \mathrm{kg} / \mathrm{km}^{2} / \mathrm{month}$ per year, $\left.\mathrm{P}=0.003\right)$ during follow-up, and there was a difference of borderline significance between the two communities in the slope of concentration of $\mathrm{NO}_{2}\left(0.033(-0.013\right.$ to 0.079$) \mu \mathrm{g} / \mathrm{m}^{3}$ per year, $\mathrm{P}=0.092)$ and sulphation rate $(0.020(-0.001$ to 0.041$) \mu \mathrm{g} \mathrm{SO} / 100 \mathrm{~cm}^{2} \mathrm{PbO}_{2} /$ day/year, $\left.\mathrm{P}=0.059\right)$.

Most baseline demographic characteristics of participants who completed questionnaires during followup were comparable between the two communities, except for occupational dusts/gases/fumes exposure $(\mathrm{P}<0.001)$ (table 2). Similar results were observed among those 860 people who had completed acceptable spirometry tests (data not shown).

\section{$\mathrm{FEV}_{1}$ and $\mathrm{FEV}_{1} / \mathrm{FVC}$ ratio}

During follow-up, the mean rate of decline in $\mathrm{FEV}_{1}$ was about $19 \mathrm{ml}$ and $0.9 \%$ of the predicted value per 
Table 3 Difference between two communities in annual rate of decline in $\mathrm{FEV}_{1}(\mathrm{ml} /$ year, predicted \%/year) and $\mathrm{FEV}_{1} / \mathrm{FVC}$ ratio (\%/year) in participants aged $\geq 40$

\begin{tabular}{|c|c|c|c|c|c|c|}
\hline & \multicolumn{2}{|c|}{$\begin{array}{c}\text { Intervention } \\
\text { community }\end{array}$} & \multicolumn{2}{|c|}{$\begin{array}{l}\text { Control } \\
\text { community }\end{array}$} & \multicolumn{2}{|c|}{ Adjusted difference* } \\
\hline & No & Mean (SE) & No & Mean (SE) & Mean $(95 \% \mathrm{Cl})$ & $P$ value \\
\hline \multicolumn{7}{|l|}{ Total population } \\
\hline $\mathrm{FEV}_{1}(\mathrm{ml} /$ year) & 429 & $30(3)$ & 431 & $49(3)$ & 19 (3 to 36$)$ & 0.023 \\
\hline $\mathrm{FEV}_{1}$ (predicted \%/year) & 429 & $0.3(0.2)$ & 431 & $1.2(0.2)$ & $0.9(0.1$ to 1.8$)$ & 0.033 \\
\hline $\mathrm{FEV}_{1} / \mathrm{FVC}(\% /$ year $)$ & 429 & $-0.5(0.1)$ & 431 & $0.4(0.1)$ & $0.6(0.1$ to 1.2$)$ & 0.029 \\
\hline \multicolumn{7}{|l|}{ Participants without COPD } \\
\hline $\mathrm{FEV}_{1}(\mathrm{ml} /$ year) & 382 & $26(3)$ & 379 & $50(3)$ & 20 (3 to 37$)$ & 0.025 \\
\hline $\mathrm{FEV}_{1}$ (predicted \%/year) & 382 & $0.1(0.2)$ & 379 & $1.2(0.2)$ & $1.1(0.2$ to 2.0$)$ & 0.021 \\
\hline $\mathrm{FEV}_{1} / \mathrm{FVC}(\% /$ year) & 382 & $-0.5(0.1)$ & 379 & $0.4(0.1)$ & 0.7 (0.1 to 1.2$)$ & 0.019 \\
\hline
\end{tabular}

*Adjusted for baseline $\mathrm{FEV}_{1}$ (or FEV 1 /FVC), age, sex, education, smoking status, COPD, BMI (body mass index), and occupational exposure to dusty/gases/fumes) and clustering effects.

year higher in the control community than in the intervention community (49 $\mathrm{ml} /$ year $v 30 \mathrm{ml} /$ year; $1.2 \%$ v $0.3 \%$ of predicted values per year). The $\mathrm{FEV}_{1} / \mathrm{FVC}$ ratio declined in the control community but not in the intervention community $(0.4 \% \quad v-0.5 \%$ a year $)$. After adjustment for confounders and clustering effects, statistical effects persisted for intervention community in the rate of decline $(\mathrm{P}<0.05$, table 3 and fig 3$)$. At the end of the study the intervention community had a significantly greater estimated mean $\mathrm{FEV}_{1}$ and $\mathrm{FEV}_{1} / \mathrm{FVC}$ ratio than the control community $(\mathrm{P}<0.05$, fig 3$)$. In the total population, the differences were $71 \mathrm{ml}(95 \%$ confidence interval 47 to 94$)$ for $\mathrm{FEV}_{1}$, $3.0 \%(1.7 \%$ to $4.2 \%)$ for predicted value, and $3.1 \%$ $(2.4 \%$ to $3.9 \%)$ for $\mathrm{FEV}_{1} / \mathrm{FVC}$ ratio. Similar results were observed among participants without COPD, with figures of $85 \mathrm{ml}$ (61 to $110,4.3 \%$ (3.0\% to $5.6 \%$ ), and $3.0 \%(2.3 \%$ to $3.8 \%)$, respectively (fig 3$)$.

Further subgroup analyses showed similar results in the rate of decline of $\mathrm{FEV}_{1}$ and the change of $\mathrm{FEV}_{1}$ / FVC ratio with regard to the effects of intervention among people without COPD (table 3 and fig 3). Results were also similar in participants at high risk (see table B in appendix 3 on bmj.com). There was no significant difference between patients with COPD from the two communities in the rate of decline of $\mathrm{FEV}_{1}$ within four years or in $\mathrm{FEV}_{1} / \mathrm{FVC}$ ratio (table $\mathrm{B}$ in appendix 3 on bmj.com).

As shown in the subgroup analysis of smoking, in intervention communities the decline in $\mathrm{FEV}_{1}$ values (both absolute value $(\mathrm{ml})$ and percentage of predicted value (\% predicted)) was slower in those who had never smoked or had quit smoking than in current smokers after adjustment for confounders and clustering effects $(\mathrm{P}<0.05$, table $\mathrm{C}$ in appendix 3 on bmj.com). A similar pattern but with no difference in decline of $\mathrm{FEV}_{1}$ was founded among subgroups by smoking status in the control community (table $\mathrm{C}$ in appendix 3 on bmj.com).

Further analysis of non-smokers (including never smokers and former smokers) showed that non-smokers with reported improvement in exposure to environmental tobacco smoke seemed to have a slower rate of decline of $\mathrm{FEV}_{1}$ by $0.6 \%$ of predicted value per year than those without any improvement, after adjustment for confounders and clustering effects (table D in appendix 3 on bmj.com). Non-smokers in the intervention community still had a slower rate of decline of $\mathrm{FEV}_{1}$ than those in the control community by $23 \mathrm{ml}$ (12 to 33$)$ per year and $1.2 \%(0.7 \%$ to $1.8 \%)$ of predicted value per year) (table $\mathrm{D}$ in appendix 3 on bmj.com). Differences between the two communities in current smokers were smaller (data not shown).

\section{Changes in awareness of and risk factors for COPD}

By the end of the study, awareness of COPD in the intervention community improved from $20 \%$ to $77 \%$ compared with $18 \%$ to $22 \%$ in the control community $(\mathrm{P}<0.001)$. Similarly, more people reported awareness of the risks or hazards of cigarette smoking, despite no significant difference for awareness of COPD and related risk factors at baseline (table 1 and table 4).

Compared with the control community, more people in the intervention community reported an improvement in outdoor air pollution (27\% $v 19 \%)$, working conditions ( $6 \%$ v 3\%), and environmental tobacco smoke $(61 \% v 52 \%)$ (table 4$)$. The rate of smoking cessation in intervention community was $21 \%$, which is higher than that in the control community $(8 \%)$ (table 4). Although there were no significant differences between the two communities in cumulative incidence of COPD (both around 4\%) and cumulative death rate of COPD $(2 \% v 11 \%)$, there were differences in cumulative death rate from all causes in the total population during follow-up $(1 \%$ v $3 \%, \mathrm{P}=0.009)$ (table 4). We found no overall difference with regard to quality of life (scores of St George's respiratory questionnaire) among patients with COPD between two communities. Patients with COPD who had received integrated intervention for a year, however, showed improved quality of life as indicated in symptom scores on the respiratory questionnaire and experienced less exacerbation of COPD compared with those in the control community (data not shown).

\section{Changes of outdoor air quality}

As shown in figure 2, there was a greater decline in $\mathrm{SO}_{2}$ concentration (0.051 (0.019 to 0.083$) \mu \mathrm{g} / \mathrm{m}^{3}$ per year, $\mathrm{P}<0.003)$ and dust deposition $(0.051$ (0.019 to 0.083$)$ $\mathrm{kg} / \mathrm{km}^{2} /$ month per year, $\left.\mathrm{P}<0.003\right)$ in the intervention community than in the control community. There were borderline differences between the two communities in the slope of concentration of $\mathrm{NO}_{2}(0.033$ $(-0.013$ to 0.079$) \mu \mathrm{g} / \mathrm{m}^{3}$ per year, $\left.\mathrm{P}>0.09\right)$ and sulphation rate $\left(0.020(-0.001\right.$ to 0.041$) \mu \mathrm{g} \mathrm{SO}_{3} / 100 \mathrm{~cm}^{2}$ $\mathrm{PbO}_{2}$ /day/year, $\left.\mathrm{P}>0.05\right)$. These results indicate that outdoor air quality was significantly improved in intervention community compared with the control community.

\section{DISCUSSION}

\section{Principal findings and comparison}

Community based integrated intervention at earlier stages of COPD and before its development could significantly slow the decline in $\mathrm{FEV}_{1}$. To our knowledge, 

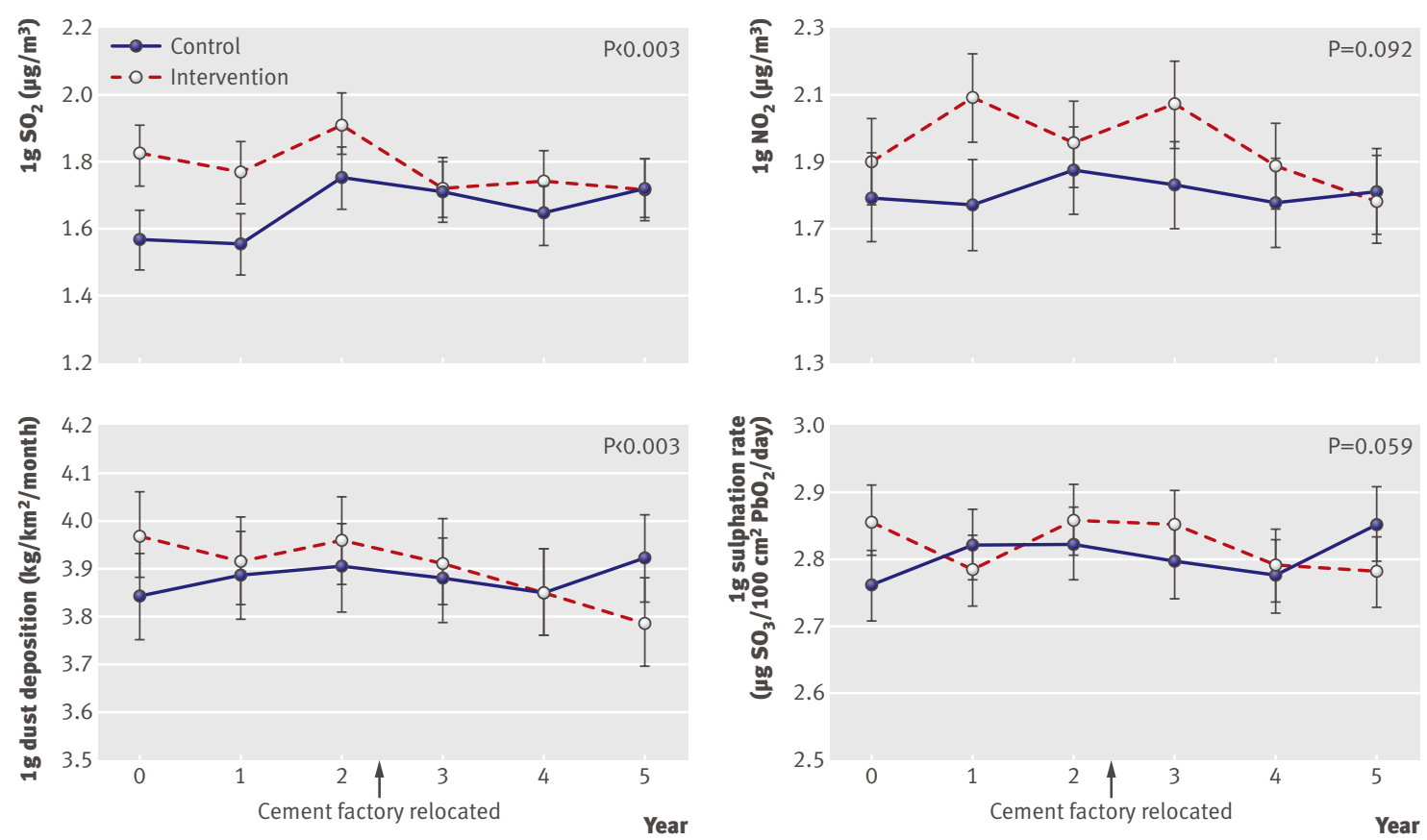

Fig 2 | Annual log mean levels of air pollutants in intervention and control communities, 2002-2007, with 95\% confidence intervals

few studies have directly elucidated the effects of integrated intervention on COPD at the community level. The multiple risk factor intervention trial (MRFIT), ${ }^{19}$ which focused on coronary heart disease, found no overall differences in the rate of decline in $\mathrm{FEV}_{1}$ between two communities (usual care and special intervention that included an intensive smoking cessation programme), but $\mathrm{FEV}_{1}$ declined slowly among smokers who did not take $\beta$ blockers in the tobacco cessation intervention group compared with controls. In Lung Health Study, ${ }^{20}$ aggressive smoking interventions were given to smokers with mild COPD, and this resulted in a slower decline in $\mathrm{FEV}_{1}$ in the first year between the two groups, but there were no differences in the next three years. In contrast, our community based interventions targeted more aspects of COPD management and prevention at its earlier stages or before development. As a result, we saw a slower rate of decline in $\mathrm{FEV}_{1}$ among participants in the intervention community than in the control community. Meanwhile, there was an improvement in $\mathrm{FEV}_{1} / \mathrm{FVC}$ ratio among participants in intervention community, especially among those at high risk of COPD.

The benefits of our integrated intervention could have resulted from a combination of smoking cessation, efforts to improve environmental air quality, self management training for prevention of COPD, and other positive factors.

\section{Smoking}

Smoking accelerates the decline in $\mathrm{FEV}_{1}$, but it can be reversed by quitting smoking. ${ }^{619-23}$ In our study there was a greater cessation rate in the intervention community than in the control community $(21 \% v 8 \%)$. Cessation was associated with a reduced rate of decline in
$\mathrm{FEV}_{1}$ (by $-27 \mathrm{ml} /$ year) in the intervention community (table $\mathrm{C}$ in appendix 3 on bmj.com). In the control community, there was no significant difference in annual rate of decline in $\mathrm{FEV}_{1}$ between those who did and did not stop smoking, which could be explained by the low numbers of participants who had quit smoking and the fact that some of them gave up smoking because of worsening health status. Therefore, there seems little question that smoking cessation greatly contributed to the outcome of the intervention.

Other factors besides smoking cessation should also strengthen the positive benefits of intervention. We found a significant difference in the rate of decline in $\mathrm{FEV}_{1}$ between the two communities after adjustment for smoking cessation, as well as in non-smokers (table $\mathrm{D}$ in appendix 3 on bmj.com). As shown in our results, more people reported having improved exposure to environmental tobacco smoke from baseline in the intervention community than in control community during follow-up. Those who reported having reduced exposure to environmental tobacco smoke at the end of study had a slower rate of decline in $\mathrm{FEV}_{1}$ than those without reduced exposure (table D in appendix 3 on bmj.com). These observations indicated that changes in exposure to environmental tobacco smoke might have contributed to the effects of intervention.

\section{Air pollution}

As an important part of the community based intervention programme and after joint efforts of members of the study team, public, and government, a neighbourhood cement factory near the intervention community was eventually relocated and upgraded in 2005 with the main purpose of decreasing air pollution. This resulting improvement in outdoor air pollution was 

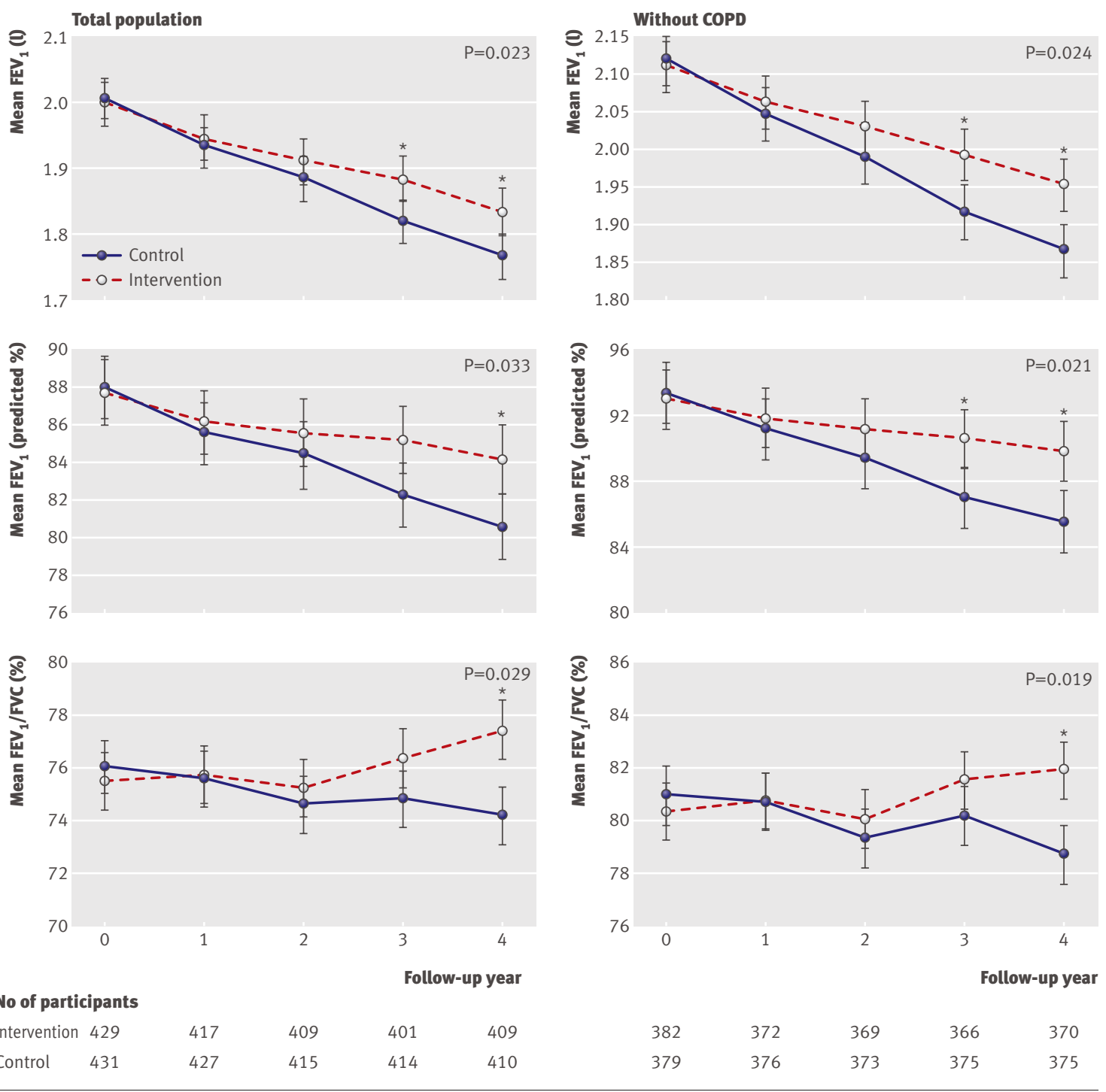

No of participants

Intervention 429

417

Follow-up year

Control 431

427

409

401

409

Fig 3 Estimated mean $\mathrm{FEV}_{1}$ ( $\mathrm{ml}$ and \% predicted) and $\mathrm{FEV}_{1} / \mathrm{FVC}$ ratio (\%) over time in both communities among total population and those without COPD. *P<0.05 for estimated mean after adjustment for clustering and confounding factors (baseline $\mathrm{FEV}_{1}$ (or $\mathrm{FEV}_{1} / \mathrm{FVC}$ ratio), age, sex, education, smoking status, environmental tobacco smoke, COPD, BMI, and occupational exposure to dust/gases/fumes). $\mathrm{P}$ values in figure refer to comparison between communities in rate of decline in $\mathrm{FEV}_{1}$ and $\mathrm{FEV}_{1} / \mathrm{FVC}$ ratio after adjustment for above confounders and clustering effects

noted in laboratory reports from a perennial monitoring site in the intervention community designated by the local bureau of environmental protection (fig 2). In contrast, data from the monitoring site in the control community showed no improvement in air quality. After adjustment for potential confounders and cluster effects, there were still significant differences in the surrogates for the change in outdoor air quality between the two communities, and similar results were observed among those who had never smoked (table $\mathrm{D}$ in appendix 3 on bmj.com). In addition, there was significant correlation between adjusted $\mathrm{FEV}_{1}$ and $\mathrm{FEV}_{1} / \mathrm{FVC}$ ratio and averaged air pollutants over time (table $\mathrm{E}$ in appendix 3 on bmj.com). Therefore, improvement in air pollution within the intervention community should also have contributed to the slower decline in $\mathrm{FEV}_{1}$, which is consistent with previous published literature. ${ }^{24}$

\section{Education and knowledge}

Though health education did not seem to have obvious and directly positive effects on the rate of decline in $\mathrm{FEV}_{1}$ (data not shown), previous trials have shown that it can help to reduce exacerbation of and mortality from COPD and improve quality of life. ${ }^{92526}$ As lower respiratory disorders or acute exacerbations of COPD also promote decline in $\mathrm{FEV}_{1}$ in current smokers with mild COPD,${ }^{27}$ reduction in acute exacerbations should also have a positive effect on decline of $\mathrm{FEV}_{1}$. Furthermore, as COPD is considered a disease in which limitation of air flow associated with harmful gases and fumes is not fully reversible, education targeted at avoidance of risk factors might have played an important role in reducing the decline of $\mathrm{FEV}_{1}$. At baseline $78 \%$ of the participants knew little about COPD and over $65 \%$ had never received health education. This poor level of COPD prevention among people at baseline could 
Table $4 \mid$ Awareness of health knowledge, change of risk factors, cumulative incidence rate, and case death rate between two communities after intervention

\begin{tabular}{|c|c|c|c|c|}
\hline & $\begin{array}{c}\text { Intervention } \\
\text { community }(n=436)\end{array}$ & $\begin{array}{l}\text { Control community } \\
\qquad(n=436)\end{array}$ & $\begin{array}{l}\text { Adjusted odds ratio } \\
(95 \% \mathrm{Cl})^{\star}\end{array}$ & P value \\
\hline \multicolumn{5}{|l|}{ Awareness of COPD†: } \\
\hline Not aware & $78(23)$ & $259(78)$ & Reference & - \\
\hline Aware & $263(77)$ & $72(22)$ & 12.13 (8.46 to 17.39$)$ & $<0.001$ \\
\hline \multicolumn{5}{|c|}{ Awareness of smoking hazard†: } \\
\hline Not aware & $27(8)$ & 57 (17) & Reference & - \\
\hline Know a little & $125(37)$ & $125(38)$ & $2.11(1.25$ to 3.56$)$ & 0.005 \\
\hline Know more & $189(55)$ & $149(45)$ & 2.68 (1.61 to 4.44$)$ & $<0.001$ \\
\hline \multicolumn{5}{|c|}{ Outdoor air pollutionł: } \\
\hline Improved & $115(27)$ & $83(19)$ & 1.42 (1.02 to 1.98$)$ & 0.039 \\
\hline No change & $241(56)$ & $247(57)$ & Reference & - \\
\hline Worsened & $76(18)$ & $105(24)$ & $0.74(0.53$ to 1.05$)$ & 0.091 \\
\hline \multicolumn{5}{|l|}{ Working conditions: } \\
\hline Improved & $24(6)$ & $14(3)$ & 1.73 (0.88 to 3.39$)$ & 0.113 \\
\hline No change & 407 (93) & $410(94)$ & Reference & - \\
\hline Worsened & $5(1)$ & $12(3)$ & $0.42(0.15$ to 1.20$)$ & 0.106 \\
\hline \multicolumn{5}{|c|}{ Environmental exposure to tobacco smoke§: } \\
\hline Improved & $262(61)$ & $222(52)$ & $1.48(1.32$ to 1.68$)$ & $<0.001$ \\
\hline Not improved & $167(39)$ & $209(49)$ & Reference & - \\
\hline \multicolumn{5}{|c|}{ Smoking status at end of study: } \\
\hline Never smoker & $241(55)$ & $235(54)$ & Reference & - \\
\hline Current smoker & $95(22)$ & $129(30)$ & $0.72(0.52$ to 0.99$)$ & 0.045 \\
\hline Stopped smoking & $100(23)$ & $72(17)$ & $1.36(0.95$ to 1.93$)$ & 0.092 \\
\hline \multicolumn{5}{|c|}{ Stopped smoking during study period: } \\
\hline No & $93(79)$ & $127(92)$ & Reference & - \\
\hline Yes & $25(21)$ & $11(8)$ & $3.10(1.44$ to 6.67$)$ & $<0.004$ \\
\hline \multicolumn{5}{|c|}{ Cumulative incidence of COPD** } \\
\hline Yes & $16(4)$ & $16(4)$ & $0.98(0.49$ to 2.00$)$ & 0.964 \\
\hline No & $369(96)$ & $358(96)$ & Reference & - \\
\hline \multicolumn{5}{|c|}{ Cumulative deaths from COPD } \\
\hline Yes & $1(2)$ & $6(11)$ & $0.17(0.02$ to 1.50$)$ & 0.120 \\
\hline No & $47(98)$ & $47(89)$ & Reference & - \\
\hline \multicolumn{5}{|c|}{ Cumulative deaths from all causes } \\
\hline Yes & $6(1)$ & $15(3)$ & $0.23(0.08$ to 0.69$)$ & $<0.009$ \\
\hline No & $430(99)$ & $421(97)$ & Reference & - \\
\hline
\end{tabular}

*Adjusted for clustering effects. Odds ratio $>1$ means that over four years more people in intervention community than control community reported improvement in variables. After adjustment for clustering effect, when variables were considered as ordered categories and cumulative logit model was used, odd ratios were 1.66 (1.24 to 2.22, P<0.001) for awareness of hazards of smoking, 1.52 (1.17 to 1.97, P<0.002) for outdoor air pollution, and 1.94 (1.09 to $3.44, \mathrm{P}=0.024)$ for working conditions.

†After intervention 341 in intervention community and 331 in control community randomly sampled from entire population completed short questionnaire of knowledge on health.

†Data missing for four in intervention community and one in control community.

§Data missing for seven in intervention community and five in control community.

TFour former smokers at baseline (two in each community) had started smoking at end of study.

**Diagnosis of COPD was according to global obstructive lung disease in 12 participants. Excludes participants who did not undergo post-bronchodilator test and those with pre-bronchodilator $\mathrm{FEV}_{1} / \mathrm{FVC} \geq 70 \%$.

also explain the greater outcomes achieved by this well designed health education programme in our integrated intervention.

\section{Strengths and limitation of the study}

Our integrated community based intervention achieved positive effects, especially for people at high risk of COPD. As COPD is a disease that can be caused by multiple factors, an integrated intervention, which was formed and refined from published methods (such as smoking cessation, reduce of air pollution, rehabilitation, nutrition support, drug treatment, and health education), ${ }^{6-91920}$ should be more effective regarding development and progression of the disease than a single intervention targeted at a sole factor. COPD has a long term course with chronic progression and is often underdiagnosed, and thus a community based integrated intervention at earlier stages or before development of COPD would have more impact than a hospital intervention among patients who have already developed moderately or severely symptomatic COPD. Our hypothesis is consistent with the results of several recent studies. ${ }^{28-30}$ These studies have shown that $\mathrm{FEV}_{1}$ declined more rapidly in patients with milder COPD, indicating that more attention should be paid to patients with earlier stage disease. Our results further emphasise the importance of intervention before the development of COPD.

Our study had certain limitations. Firstly, fewer participants in the intervention community had occupational exposure to dust/gases/fumes at baseline. We consider that this imbalance did not compromise our conclusion because we found a significantly slower rate of decline in $\mathrm{FEV}_{1}$ in the intervention community even after adjustment for these factors. This was also the case in further analyses stratified by occupational exposure to dust/gases/fumes (fig A in appendix 4 on bmj.com). Secondly, changes in risk factors such as smoking status were not based on laboratory measurement but on self report. This did not change our conclusions as we also obtained information from close family members of the participants. Our results also showed that smoking cessation slowed the rate of decline in $\mathrm{FEV}_{1}$ (table $\mathrm{B}$ in appendix 3 on bmj.com), confirming results of other studies. ${ }^{619-21}$ In addition, despite there being a correlation between adjusted $\mathrm{FEV}_{1}$ and air pollutants over time (table E in appendix 3 on bmj.com), we could not further confirm the correlation of annual rate of decline in $\mathrm{FEV}_{1}$ and change of outdoor air quality because we recruited only two communities. Finally, we evaluated the annual decline of $\mathrm{FEV}_{1}$ only before use of a bronchodilator, not after, because a bronchodilator test was not performed among patients without COPD at baseline. COPD was defined by a $\mathrm{FEV}_{1}$ / FVC ratio of below 0.7 after use of bronchodilator. This criterion, however, could result in overdiagnosis in older people and underdiagnosis in younger people. ${ }^{31}$ Diagnosis by percentage of $\mathrm{FEV}_{1} / \mathrm{FVC}$ ratio below the fifth centile should be more precise. ${ }^{32}$ Unfortunately, the lower limit of normal for $\mathrm{FEV}_{1}$ / FVC ratio for people in China is not currently available. In addition, a fixed ratio of $\mathrm{FEV}_{1} / \mathrm{FVC}$ below 0.7 is still recommended by the global initiative for chronic obstructive lung disease (GOLD) and is used by many other investigators. ${ }^{333}$ We therefore used the fixed ratio of 0.7 for diagnosis of COPD in our study.

\section{Conclusion and implications}

In conclusion, this community based integrated intervention helped to prevent and control COPD through improved awareness of COPD, reduced risk factors for $\mathrm{COPD}$, and a reduction of the rate of decline in $\mathrm{FEV}_{1}$. 


\section{WHAT IS ALREADY KNOWN ON THIS TOPIC}

COPD is a chronic progressive disease caused by multiple factors such as smoking and air pollution; a single factor intervention will therefore have limited effects

Little attention has been paid to interventions at an earlier stage at community based level

\section{WHAT THIS STUDY ADDS}

Community based integrated interventions can decrease the rate of decline in $\mathrm{FEV}_{1}$, probably from the combined effects of smoking cessation and improvements in air pollution

Though the methods used in this integrated intervention and our experience with it might be culture and condition specific, the outcomes that smoking cessation, improvement in air pollutants, and reduction in environmental tobacco smoke have contributed to the slowing rate of decline in $\mathrm{FEV}_{1}$ should apply throughout the world.

We thank Xiaoyi Yang (National Cancer Institute, $\mathrm{NIH}$, USA) and Guangqiao Zeng (State Key Laboratory of Respiratory Disease, Guangzhou Institute of Respiratory Diseases, Guangzhou Medical University, China) for their help with English, and Mei Jiang (State Key Laboratory of Respiratory Disease, Guangzhou Institute of Respiratory Diseases, Guangzhou Medical University, China) for her help with the statistical analysis. We also thank Jinquan Liang, Tianming Dong, and Yexin Liu (Bureau of Environmental Protection of Liwan District, Guangzhou Environmental Monitoring Center, Bureau of Environmental Protection of Guangzhou Municipality) for their help in measuring air pollution.

Contributors: $Y Z$ collected the data and monitored data collection, planned the statistical analysis, analysed the data, and drafted and revised the manuscript. GH and DW implemented the trial and conducted the intervention. SW, YW, and ZL conducted and monitored data collection. JH and ZS conducted intervention. GP and SL conducted data collection. JL planned the statistical analysis and drafted and revised the paper. JZ monitored data collection and drafted and revised the paper. JW drafted and revised the paper. PR and NZ initiated and designed the project, monitored data, and drafted and revised the paper. PR, NZ, and $\mathrm{YZ}$ are guarantors.

Funding: This study was funded by a grant from the Chinese Central Government key research projects of the 10th National Five-year Development Plan 2001BA703B03(A) and in part by Guangdong Key Research Project grant B30301. The researchers were independent from funders. The study funders had no influence on the study design, collection, analysis, interpretation of data, writing of the report, and the decision to submit the article for publication.

Competing interests: All authors have completed the Unified Competing Interest form at www.icmje.org/coi_disclosure.pdf (available on request from the corresponding author) and declare: no support from any institution for the submitted work; no financial relationships with any institutions that might have an interest in the submitted work in the previous 3 years; no other relationships or activities that could appear to have influenced the submitted work.

Ethical approval: The study protocol was approved by medical ethic committee of Guangzhou Institute of Respiratory Diseases and written informed consent was given by all participants.

Data sharing: No additional data available.

1 Sin DD, Stafinski The impact of chronic obstructive pulmonary disease on work loss in the United States. Am J Respir Crit Care Med 2002;165:704-7.

2 Lopez AD, Murray CC. The global burden of disease, 1990-2020. Nat Med 1998;4:1241-3.

3 Buist AS, McBurnie MA, Vollmer WM, Gillespie S, Burney P, Mannino DM, et al. International variation in the prevalence of COPD (the burden of obstructive lung disease study): a population-based prevalence study. Lancet 2007;370:741-50.

4 Zhong N, Wang C, Yao W, Chen P, Kang J, Huang S, et al. Prevalence of chronic obstructive pulmonary disease in China-a large populationbased spirometry based cross-sectional survey. Am J Respir Crit Care Med 2007;176:753-60.
5 Chan-Yeung M, Aït-Khaled N, White N, Ip MS, Tan WC. The burden and impact of COPD in Asia and Africa. Int J Tuberc Lung Dis 2004;8:2-14.

6 Scanlon PD, Connett JE, Waller LA, Altose MD, Bailey WC, Buist AS. Smoking cessation and lung function in mild-to-moderate chronic obstructive pulmonary disease. The Lung Health Study. Am J Respir Crit Care Med 2000;161:381-90.

7 Tabak C, Smit HA. Diet and chronic obstructive pulmonary disease: independent beneficial effects of fruits, whole grains, and alcohol (the MORGEN study) Clin Exp Allergy 2001;31:747-55.

8 Tashkin DP, Celli B, Senn S, Burkhart D, Kesten S, Menjoge S, et al. A 4-year trial of tiotropium in chronic obstructive pulmonary disease. $N$ Engl / Med 2008;359:1543-54

9 Troosters T, Casaburi R, Gosselink R, Decramer M. Pulmonary rehabilitation in chronic obstructive pulmonary disease. Am J Respir Crit Care Med 2005;172:19-38.

10 Calverley PM, Anderson JA, Celli B, Ferguson GT, Jenkins C, Jones PW, et al. Salmeterol and fluticasone propionate and survival in chronic obstructive pulmonary disease. N Engl/ Med 2007;356:775-89.

11 Zhou Y, Wang C, Yao W, Chen P, Kang J, Huang S, et al. COPD in Chinese nonsmokers. Eur Respir J 2009;33:509-18.

12 Gu D, Wu X, Reynolds K, Duan X, Xin X, Reynolds RF, et al. Cigarette smoking and exposure to environmental tobacco smoke in China: the international collaborative study of cardiovascular disease in Asia. Am J Public Health 2004;94:1972-6.

13 Yang G, Fan L, Tan J, Qi G, Zhang Y, Samet JM, et al. Smoking in China, finding of the 1996 national prevalence of survey. JAMA 1999;282:1247-53.

14 American Thoracic Society. Standardization of spirometry. 1994 update. Am J Respir Crit Care Med 1995;152:1107-36.

15 Pellegrino R, Viegi G, Brusasco V, Crapo RO, Burgos F, Casaburi R, et al. Interpretative strategies for lung function tests. Eur Respir J 2005;26:948-68.

16 Rabe KF, Hurd S, Anzueto A, Barnes PJ, Buist SA, Calverley P, et al. Global strategy for the diagnosis, management, and prevention of chronic obstructive pulmonary disease: GOLD executive summary. Am J Respir Crit Care Med 2007;176:532-55

17 Zheng J, Zhong N. Normative values for pulmonary function testing in Chinese adults. Chin Med) (Engl) 2002;115:50-4.

18 Donner A, Klar N. Design and analysis of cluster randomization trials in health research. Oxford University Press, 2000.

19 Browner WS, DuChene AG, Hulley SB. Effects of the Multiple Risk Factor Intervention Trial smoking cessation program on pulmonary function - a randomized controlled trial. West/Med 1992;157:534-8

20 Anthonisen NR, Connett JE. Effects of smoking intervention and the use of an inhaled anticholinergic bronchodilator on the rate of decline of FEV ${ }_{1}$ the lung health study. JAMA 1994:272:1497-505.

21 Willemse BW, Postma DS, Timens W, ten Hacken NH. The impact of smoking cessation on respiratory symptoms, lung function, airway hyperresponsiveness and inflammation. Eur Respir 2004;23:464-76.

22 Omori H, Nonami Y, Morimoto Y. Effect of smoking on $\mathrm{FEV}_{1}$ decline in a cross-sectional and longitudinal study of a large cohort of Japanese males. Respirology 2005;10:464-9.

23 Tager I, Segal MR, Speizer FE, Weiss ST. The natural history of forced expiratory volumes-Effect of cigarette smoking and respiratory symptoms. Am Rev Respir Dis 1988;138:837-49.

24 Gauderman WJ, Avol E, Gilliland F, Vora H, Thomas D, Berhane K, et al. The effect of air pollution on lung development from 10 to 18 years of age. N Engl J Med 2004;351:1057-67. [Erratum in N Engls Med 2005;352:1276.

25 Garcia-Aymerich J, Hernandez C, Alonso A, Casas A Rodriguez-Roisin R, Anto JM, et al. Effects of an integrated care intervention on risk factors of COPD readmission. Respir Med 2007;101:1462-9.

26 Casas A, Troosters T, Garcia-Aymerich J, Roca J, Hernadez C, Alonso A et al. Integrated care prevents hospitalisations for exacerbations in COPD patients. Eur Respir / 2006;28:123-30

27 Kanner RE, Anthonisen, Connet JE. Lower respiratory illnesses promote $\mathrm{FEV}_{1}$ decline in current smokers, but not ex-smokers with mild chronic obstructive pulmonary disease: results from the Lung Health Study. Am J Respir Crit Care Med 2001;164:358-64.

28 Decramer M, Celli B, Kesten S, Lystig T, Mehra S, Tashkin DP, et al. Effect of tiotropium on outcomes in patients with moderate chronic obstructive pulmonary disease (UPLIFT): a prespecified subgroup analysis of a randomized controlled trial. Lancet 2009;374:1171-8.

29 Celli B, Thomas N, Anderson J, Ferguson JT, Jenkins CR, Jones PW, et al. Effect of pharmacotherapy on rate of decline of lung function in chronic obstructive pulmonary disease. Am J Respir Crit Care Med 2008;178:332-8.

30 Bridevaux PO, Gerbase MW, Probst-Hensch NM, Schindler C, Gaspoz JM, Rochat T. Long-term decline in lung function, utilisation of care and quality of life in modified GOLD stage 1 COPD. Thorax 2008;63:768-74. 
31 Hansen JE, Sun XG, Wasserman K. Spirometric criteria for airway obstruction: Use percentage of FEV1/FVC ratio below the fifth percentile, not $<70 \%$. Chest 2007;131:349-55.

32 Swanney MP, Ruppel G, Enright PL, Pedersen OF, Crapo RO, Miler JR, et al. Using the lower limit of normal for the FEV1/FVC ratio reduces the misclassification of airway obstruction. Thorax 2008;63:1046-51
33 Menezes AM, Perez-Padilla R, Jardim JR, Muino A, Lopez MV, Valdivia G, et al. Chronic obstructive pulmonary disease in five Latin American cities (the PLATINO study): a prevalence study. Lancet 2005;366:1875-81.

Accepted: 18 September 2010 